IRSTI $34.43 .35 ; 61.45 .31$

\author{
${ }^{1 *}$ L.K. Baktybayeva, ${ }^{1}$ M.K. Tauassarova, ${ }^{1}$ B.K. Kairat, ${ }^{2}$ B.K. Darrell, \\ ${ }^{1}$ N.B. Baktybay, ${ }^{3}$ V.K. Yu, ${ }^{3}$ A.G. Zazybin, ${ }^{3}$ A.E. Malmakova \\ ${ }^{1}$ Laboratory of ecological physiology, Almaty, Kazakhstan \\ ${ }^{2}$ Oklahoma State University, Center for Health Sciences, Stillwater, Oklahoma City, USA \\ ${ }^{3}$ A.B. Bekturov Institute of Chemical Sciences, Laboratory of chemistry of synthetic and natural drugs; \\ Kazakh-British Technical University, School of Chemical Engineering, Almaty, Kazakhstan \\ *e-mail: Layilia.Baktybaeva@kaznu.kz

\section{Myeloid poiesis stimulating activity of azaheterocycles compound of the dimethyl ether of P-(4-methoxyphenyl)-1-(4-phenylpiperazine) methyl] phosphonic acid}

\begin{abstract}
Development of new effective drugs with myeloid poiesis stimulating activity is highly relevant due to the increase in the number of patients with hematological disorders. Acquired hematological diseases are associated with unbalanced and inadequate nutrition, chronic blood loss, living in ecologically disadvantaged areas, extreme physical activity, use of cytostatic and cytotoxic drugs, chronic stress, and other. Azaheterocyclic compounds are perspective for search of new effective myeloid poiesis stimulating drugs. The incentive for this search was the manifestation of myeloid poiesis stimulating activity by azaheterocycles drug Prosidol (Propionylphenylethoxyethylpyperidine) in clinical practice. On the model cyclophosphamide myeloid depression high myeloid poiesis stimulating activity showed that compound of the dimethyl ether of P-(4-methoxyphenyl)-1-(4-phenylpiperazine) methyl] - phosphonic acid in laboratory coding of BIV-95. In a series of experiments showed myeloid poiesis stimulating activity at the level of comparison compound (2, 3, 5, 6-tetrahydro-6-phenylimidazo [2, 1-b] thiazole hydrochloride (Levamizol drug). The erythropoiesis stimulating activity exceeded the activity of the comparison compounds. The thrombocytopoiesis stimulating activity was at the level of the comparison compounds. Leukopoiesis stimulating activity also was slightly higher than the activity of Levamizol drug. Recovery of granulocytic and agranulocytic leukocyte were no violations of immunoregulatory index in leukogram blood. The test compound is the dimethyl ether of P-(4-methoxyphenyl)-1-(4-phenylpiperazine) methyl]-phosphinic acid compound under the laboratory coding BIV-95 had low toxicity.
\end{abstract}

Key words: azaheterocyclic compound, erythropoiesis-stimulating activity, thrombocytopoiesis stimulating activity, leukopoiesis stimulating activity.

\section{Introduction}

Humans and animals' immune system performs an important function to maintain the constancy of the body internal environment, carried out by recognizing and eliminating alien substances of antigenic nature from the body. This function of immune system is carried out with the congenital and acquired immunity factors. Different types of radiation, heavy metal salts, vitamin and micronutrient deficiency, stressful situations, age-related changes in the lymph myeloid complex, therapy with anti-tuberculosis, antibacterial, hormonal, cytostatic drugs and a number of other factors lead to the development of immune diseases. These diseases treated with a set of immunotherapy methods, the use of immunostimulants is one of them. Today, immunostimulants distinguish such of microbial, thymus, bone marrow, cytokines, nucleic acids, vegetable and synthetic origin. Many immunostimulants have a wide range of side effects $[1 ; 2]$. Preparations from thymus cause severe allergic reactions [3; 4]. Preparations based on nucleic acids cause uncontrolled division of all cells of the body: benign, malignant, bacterial microflora $[5 ; 6]$. Preparations of plant origin require long-term systemic use [7]. With introduction of medicinal interleukins it is difficult to control the reaction of the body, which in a negative case can result in septic shock [5]. 
In the Republic of Kazakhstan monitoring and synthesis of new synthetic myeloid poiesis stimulating and immunostimulants preparations is carried out in the laboratory of chemistry of synthetic and natural drugs of the JSC A.B. Bekturov Institute of Chemical Sciences [3]. Staff of chemistry of synthetic and natural drugs laboratory has accumulated vast experience in the field of synthesis and chemical transformations of 4-oxipiperidines, obtained new data, which allows making important conclusions about the relationship between the fine chemical structure of synthesized compounds and their reactivity, spectral characteristics and biological activity. Drugs with high anesthetic, antiarrhythmic, anti-allergic, immunostimulatory and other types of activity were discovered having substantial advantages over the conventional medicines. The stimulus for the search among piperidine derivatives was the manifestation of immunostimulating activity by the preparation Prosidol (propionylphenylethoxyethylpyperidine), obtained in this laboratory [8]. The aim of the current study was to examine the myeloid stimulating activity and acute toxicity of dimethyl ester of P-[(4-methoxyphenyl)1-(4-phenylpiperazine) methyl] phosphinic acid compound under the laboratory coding BIV-95.

\section{Materials and methods}

Dimethyl ester of P- [(4-methoxyphenyl)-1-(4phenylpiperazine) methyl] phosphonic acid compound under the laboratory coding BIV-95 (chemical formula shown on Figure 1) was studied for leukopoiesis stimulating action and acute toxicity.

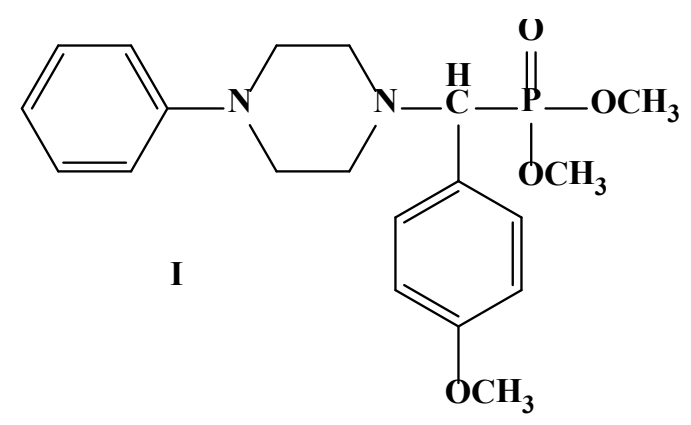

Figure 1 - Chemical formula of BIV-95

In the experiment 30 healthy $16-18$ weeks old, 210-280 g albino laboratory female rats were used. The scatter in the groups according to the initial body weight did not exceed $\pm 10 \%$. Animals were taken

Int. j. biol. chem. (Online) from the nursery of the biological clinic of the Faculty of Biology and Biotechnology of the al-Farabi Kazakh National University. Before the experiment and during it, control and experimental animals were kept in the same standard conditions, on a standard diet, with six animals in each cage. Investigations were carried out in accordance with the "Rules for the pre-clinical (non-clinical) studies of biologically active substances" and "Ethical principles and guidelines for scientific experiments on animals" [9]. Animals were divided into 5 groups of 6 animals. Group 1 was intact. Animals did not receive cytostatic and test compounds. On the $1^{\text {st }}, 3^{\text {rd }}, 5^{\text {th }}$ day of the experiment, all other groups received a cytostatic drug doxorubicin hydrochloride at a dose of $10 \mathrm{mg} / \mathrm{kg}$ of animal weight in a volume of $0.2 \mathrm{ml}[10]$. On the $8^{\text {th }}$ day of the experiment, the number of cells in the peripheral blood was counted. On the $8^{\text {th }}, 10^{\text {th }}, 12^{\text {th }}$ day of the experiment the animals of the second group were injected with BIV-95 at a dose of $5 \mathrm{mg} / \mathrm{kg}$ intraperitoneally in a volume of $0.2 \mathrm{ml}$, saline used as solvent. On the $18^{\text {th }}$ day of the experiment the number of cells in the peripheral blood was counted. Third group of animals was given as placebo, i.e. saline in a volume of $0.2 \mathrm{ml}$. Fourth group was used as control. The animals of this group were injected with (2, 3, 5, 6-tetrahydro-6-phenylimidazo [2, 1-b] thiazole hydrochloride (Levamizole drug) at a dose of 1 $\mathrm{mg} / \mathrm{kg}$ intraperitoneally in a volume of $0.2 \mathrm{ml}$, saline used as solvent [11]. Fifth group after intoxication was not administered any compounds, which controlled the physiological rate of blood cell recovery. Blood sampling was performed at 09:00 am from the orbital vein of rats in sterile hematologic tubes VF052SDK with $2 \mathrm{~mL}$ of EDTA (K2) under the mild anesthesia with ether. Blood tests were carried out on a hematology analyzer for animal blood Abacus junior VET (Diatron, Denmark). Following parameters were analyzed: WBC - white blood cell count, LY - absolute lymphocyte count; MID - absolute monocyte-eosinophil value; GRA - absolute granulocytic value; LY - comparative lymphocytic value; MI - comparative monocyte-eosinophil value; GR - comparative granulocytic value; $\mathrm{RBC}$ - red blood cell count; HGB - hemoglobin; HCT - hematocrit; $\mathrm{MCV}$ - mean corpuscular volume; $\mathrm{MCH}$ - mean corpuscular hemoglobin; $\mathrm{MCHC}$ - mean corpuscular hemoglobin concentration; RDWC - red blood cell distribution width; PLT - total platelets volume; PCT - plateletcrit; MPV - mean platelet volume; PDWC platelet distribution width.

For the dual cytological control, in order to count blood leukogram, blood smears were produced by Gi- 
emsa stain method, and counted under a microscope SA3300S immersion (magnification x100) with 100 cells per each smear sample, afterwards the relative amount of each type of the cells converted into the absolute value [12]. Statistical data processing was carried out with the reduction of the Student's confidence factor.

For the study of acute toxicity, groups of animals (by 6 in each) were injected intraperitoneally with the test compound in various doses and observed for 5 days. External signs of intoxication, duration of toxic action and time of death were recorded. For the quantitative assessment of acute toxicity, the $\mathrm{LD}_{50}$ index was calculated (the dose that caused the death of 50\% of the test animals). The comparison compound was the $(2,3,5$, 6-tetrahydro-6-phenylimidazo [2, 1-b] thiazole hydrochloride (Levamizole drug) [11]. The toxicity grade of the drug was judged by $\mathrm{LD}_{50}$ in the experimental and control groups of animals.

\section{Results and discussion}

Data on myeloid poiesis stimulating activity. Control values obtained from intact animals enrolled in the experiment maintained within the physiological norm. Leukocyte indicator $(11.1 \pm 2.51) \cdot 10^{9} / \mathrm{L}$ of blood, with lymphocytic indicator $(5.96 \pm 1.44) \cdot 10^{9} / \mathrm{L}$ of blood, which was $(53.72 \pm 0.7) \%$. Granulocyte leukocytes had a value $(4.44 \pm 0.9) \cdot 10^{9} / \mathrm{L}$ of blood with a percentage ratio in leukogram $(40.0 \pm 1.4) \%$. The lowest was a monocytic-eosinophilic index $(07.0$ $\pm 0.0) \cdot 10^{9} / \mathrm{L}$ of blood, which in relative value was $(6.28 \pm 0.4) \%$. Erythrocyte and platelet counts were normal. The erythrocyte index was $(6.5 \pm 1.2) \cdot 10^{12} / \mathrm{L}$ of blood with hemoglobin content $(140.7 \pm 1.9) \mathrm{g} / \mathrm{L}$ of blood and hematocrit $(39.8 \pm 1.5)$. The platelet count was also normal $(660.0 \pm 122.2) \cdot 10^{9} / \mathrm{L}$ of blood, as well as thrombocrit was $(0.44 \pm 0.021)$. In overall, the main blood parameters were normal (Table 1).

Table 1 - Hemogram of blood after administration of doxorubicin hydrochloride

\begin{tabular}{|c|c|c|c|c|c|c|c|c|}
\hline \multirow{2}{*}{ Complete blood count } & \multicolumn{2}{|c|}{ Control group } & \multicolumn{2}{|c|}{ Intoxication group } & \multicolumn{2}{c|}{ Intact group } & \multicolumn{2}{c|}{ Placebo group } \\
\cline { 2 - 9 } & $\mathrm{X}_{\text {avi. }}$ & $\mathrm{d}_{\text {avi. }}$ & $\mathrm{X}_{\text {avi. }}$ & $\mathrm{d}_{\text {avi. }}$ & $\mathrm{X}_{\text {avi. }}$ & $\mathrm{d}_{\text {avi. }}$ & $\mathrm{X}_{\text {avi. }}$ & $\mathrm{d}_{\text {avi. }}$ \\
\hline $\mathrm{WBC}, \cdot 10^{9} / \mathrm{L}$ & 4.15 & 1.2 & 2.37 & 0.16 & 11.1 & 2.51 & 2.79 & 0.93 \\
\hline $\mathrm{LY}, \cdot 10^{9} / \mathrm{L}$ & 2.57 & 0.83 & 1.12 & 0.2 & 5.96 & 1.1 & 1.41 & 0.9 \\
\hline $\mathrm{MID}, \cdot 10^{9} / \mathrm{L}$ & 0.22 & 0.17 & 0.12 & 0.1 & 0.70 & 0 & 0.17 & 0.1 \\
\hline $\mathrm{GRA}, \cdot 10^{9} / \mathrm{L}$ & 1.36 & 0.14 & 0.62 & 0.3 & 4.44 & 0.9 & 0.93 & 0.13 \\
\hline $\mathrm{LY}, \%$ & 62.04 & 3.93 & 47.2 & 1.8 & 53.72 & 0.7 & 50.65 & 1.65 \\
\hline $\mathrm{MI}, \%$ & 5.28 & 2.4 & 4.9 & 1.3 & 6.28 & 0.4 & 6.0 & 5.3 \\
\hline $\mathrm{GR}, \%$ & 32.68 & 4.6 & 26.18 & 4.5 & 40 & 1.4 & 43.35 & 9.3 \\
\hline $\mathrm{RBC}, \cdot 10^{12} / \mathrm{L}$ & 4.69 & 1.36 & 3.8 & 0.5 & 6.5 & 1.2 & 4.67 & 0.1 \\
\hline $\mathrm{HGB}, \mathrm{g} / \mathrm{L}$ & 86.0 & 12.0 & 90.75 & 12 & 140.7 & 1.9 & 96.0 & 1.0 \\
\hline $\mathrm{HCT}, \%$ & 24.69 & 2.7 & 21.21 & 7.79 & 39.8 & 1.5 & 28.1 & 0.84 \\
\hline $\mathrm{MCV}, \mathrm{fl}$ & 52.5 & 1.5 & 52.75 & 1.25 & 55.0 & 1.3 & 50.0 & 11.3 \\
\hline $\mathrm{MCH}, \mathrm{pg}$ & 18.45 & 0.55 & 17.45 & 1.15 & 19.0 & 3.6 & 17.0 & 0.3 \\
\hline $\mathrm{MCHC}, \mathrm{g} / \mathrm{L}$ & 349.25 & 4.0 & 347.25 & 3.0 & 350.6 & 2.8 & 342.5 & 6.5 \\
\hline $\mathrm{RDWC}$ & 12.7 & 0.4 & 13.68 & 0.5 & 14.0 & 0.8 & 13.55 & 0.22 \\
\hline $\mathrm{PLT}, \cdot 10^{9} / \mathrm{L}$ & 318.25 & 99.0 & 70.5 & 23.33 & 660.0 & 122.2 & 447.0 & 51.0 \\
\hline $\mathrm{PCT}, \%$ & 0.21 & 0.06 & 0.05 & 0.03 & 0.44 & 0.021 & 0.32 & 0.04 \\
\hline MPV, FL & 6.63 & 0.3 & 5.28 & 2.0 & 7.9 & 0.8 & 7.1 & 0.0 \\
\hline $\mathrm{PDWC}$ & 30.95 & 0.25 & 23.1 & 8.6 & 46 & 0.8 & 32.35 & 1.3 \\
\hline
\end{tabular}

The directed myeloid depressive effect of the administered doxorubicin hydrochloride led to the myeloid depressive syndrome with a drop in blood counts on the $14^{\text {th }}$ day after the last injection. The Int. j. biol. chem. (Online) overall leukocyte index was $(4.15 \pm 1.2) \cdot 10^{9} / \mathrm{L}$ of blood, i.e. with a decrease of 2.67 times $(p \leq 0.05)$ and on the $14^{\text {th }}$ day after the injection, the level of leukocytes was $(2.69 \pm 0.54) \cdot 10^{9} / \mathrm{L}$ of blood, which 
amounted to 4.12-fold drop compared to with intact animals $(p \leq 0.01)$. According to the blood leukogram, significant negative changes in the cell pools of lymphocytes, granulocytes, monocyte-eosinophil indicator can be noted. Indicators of immunocompetent cells - lymphocytes from the control value (5.96 $\pm 1.1) \cdot 10^{9} / \mathrm{L}$ of blood decreased on the $3^{\text {rd }}$ day to $(2.46 \pm 0.75) \cdot 10^{9} / \mathrm{L}$ of blood and reached $(1.99 \pm$ $0.18) \cdot 10^{9} / \mathrm{L}$ of blood, i.e. 2.99 times less $(\mathrm{p} \leq 0.05)$ on the $14^{\text {th }}$ day. Changes that are even more significant occurred in the cell populations of granulocytes: the value of $(4.44 \pm 0.9) \cdot 10^{9} / \mathrm{L}$ of blood decreased by the $3^{\text {rd }}$ day to $(1.33 \pm 0.18) \cdot 10^{9} / \mathrm{L}$ of blood, i.e. 3.34 times less $(\mathrm{p} \leq 0.01)$. A significant decrease in the absolute index of granulocytes can be explained by a significant drop in the total leukocyte index, which affected the absolute indicators of blood cells (Table 1).

On the $1^{\text {st }}$ day after injection of doxorubicin hydrochloride increase in monocytes index was observed, which can be explained by mass cell death and an increase in the functional load on monocytes. The monocyte index $(6.0 \pm 0.7) \%$ by the $1^{\text {st }}$ day after the injection of doxorubicin hydrochloride became $(7.05 \pm 1.6) \%$, but already on the $3^{\text {rd }}$ day after the injection, it fell down to $(0.6 \pm 0.0) \%$, however, on the $14^{\text {th }}$ day it was $(16.6 \pm 0.0) \%(\mathrm{p} \leq 0.01)$.

Myeloid depressive syndrome was recorded in red blood cells. Reduction of erythrocyte cells from $(6.5 \pm 1.2) \cdot 10^{12} / \mathrm{L}$ of blood with a decrease on the $1^{\text {st }}$ day to $(4.71 \pm 1.37) \cdot 10^{12} / \mathrm{L}$ by 1.38 times and a slight increase to $(5.80 \pm 0.27) \cdot 10^{12} / \mathrm{L}$ on the $3^{\text {rd }}$ day after the injection of doxorubicin hydrochloride. The trend in fluctuations of indicators on the first day and third day after injection of doxorubicin hydrochloride was observed in hemoglobin, hematocrit, mean red blood cell volume, average hemoglobin content in red blood cells, and the width of red blood cell distribution. The decline was observed on the $1^{\text {st }}$ day of 1.2-1.6 times and then with a slight increase on the $3^{\text {rd }}$ day and a further drop in all erythrocyte values of more than 1.7 times. Significant changes were recorded in platelet indices, which naturally affected the values of trombocrit, average platelet volume and platelet distribution. On the $1^{\text {st }}$ day after injection of doxorubicin hydrochloride, the level of platelets immediately fell down to $(345.0 \pm 126.0)$

$10^{9} / \mathrm{L}$ blood with the value in intact animals equal to $(660.0 \pm 122.0) \cdot 10^{9} / \mathrm{L}$ blood, i.e. 1.91 times less $(p \leq 0.05)$. By the $14^{\text {th }}$ day after injection, the platelet level decreased to $(74.5 \pm 39.5) \cdot 10^{9} / \mathrm{L}$ of blood from the baseline value $(660.0 \pm 122.0) \cdot 10^{9} / \mathrm{L}$ of blood, i.e. 8.85 times $(\mathrm{p} \leq 0.01)($ Table 1$)$. This indicator is

Int. j. biol. chem. (Online) considered critical and is characterized by spontaneous intracavitary hemorrhage and other hemophilic disorders.

It can be concluded that doxorubicin hydrochloride caused myeloid suppression syndrome and the most sensitive cells were leukocyte cells and platelets. Among leukocyte cells, lymphocytes, granulocytes, and then monocytes died first. Then, on the background of myeloid depressive syndrome, animals were injected with BIV-95. For myelostimulating activity, the following results were obtained.

Compound BIV-95 differed in average leukopoiesis stimulating activity. It stimulated leukopoiesis and the release of leukocytes from peripheral immune organs. The common leukocyte index was $(5.35 \pm 0.8) \cdot 10^{9} / \mathrm{L}$ of blood, exceeding the indicators of the placebo group $(2.79 \pm 0.92) \cdot 10^{9} / \mathrm{L}$ of blood by 1.92 times and the control group $(4.15 \pm 1.2) 10^{9} / \mathrm{L}$ of blood by 1.29 times (Table 2).

The relative indicators of blood leukogram were presented in the following form: the lymphocytic values in the group with injection of BIV-95 and the control group differed slightly and varied within the error range from $(57.22 \pm 0.9) \%$ to $(62.04 \pm 3.93) \%$; granulocytic values were also similar to each other and ranged from $(31.15 \pm 0.2) \%$ to $(32.68 \pm 4.6)$ $\%$; monocytic-eosinophilic index was higher BIV95 group equal to $(11.63 \pm 0.1) \%$, which was 2.2 times higher than the value in control group (5.28 \pm 2.4) \%. The absolute and relative indicators of lymphocytes and granulocytes were at the level of the control group or slightly exceeded. The erythrocyte and platelet indices in the injection group of the compound BIV-95 were higher than in the injection group of the comparison drug. Erythrocyte indices in BIV-95 group were $(5.4 \pm 0.1) \cdot 10^{12} / \mathrm{L}$ against the same indicator of the control group $(4.69 \pm 1.36)$. $10^{12} / \mathrm{L}$, which amounted to 1.15 times the difference. A significant difference was recorded in hemoglobin values of $(105.0 \pm 5.6) \mathrm{g} / \mathrm{L}$ versus the value of the control group of $(86.0 \pm 12.0) \mathrm{g} / \mathrm{L}$. The average volume of erythrocytes differed slightly in the experimental and control groups: $(48.2 \pm 0.6)$ vs. $(42.5 \pm$ 1.5). The average hemoglobin content in the erythrocytes of the experimental group was significantly different from the values of the control group: (17.2 $\pm 0.1)$ pg. vs. $(8.45 \pm 0.55)$ pg., i.e. 2.04 times higher.

Platelet indices in BIV-95 group and the control group were within an accepted error rate: (315.0 $\pm 9.6) \cdot 10^{9} / \mathrm{L}$ against $(318.25 \pm 99.0) \cdot 10^{9} / \mathrm{L}$. The number of platelets, the average volume of platelets and the width of the distribution of platelets in the control and experimental group did not differ much. 
Table 2 - Blood hemogram after administration of the test compounds

\begin{tabular}{|c|c|c|c|c|c|}
\hline Indicators & Intact group & Toxic group & BIV-95 & Placebo group & Control group \\
\hline $\mathrm{WBC}, \cdot 10^{9} / \mathrm{L}$ & $11.1 \pm 2.51$ & $2.69 \pm 0.54$ & $5.35 \pm 0.8$ & $2.79 \pm 0.93$ & $4.15 \pm 1.2$ \\
\hline $\mathrm{LY}, \cdot 10^{9} / \mathrm{L}$ & $5.96 \pm 1.1$ & $1.44 \pm 0.18$ & $2.98 \pm 0.1$ & $1.41 \pm 0.87$ & $2.57 \pm 0.83$ \\
\hline $\mathrm{MID}, \cdot 10^{9} / \mathrm{L}$ & $0.70 \pm 0.0$ & $0.61 \pm 0.01$ & $0.65 \pm 0.01$ & $0.17 \pm 0.1$ & $0.22 \pm 0.17$ \\
\hline $\mathrm{GRA}, \cdot 10^{9} / \mathrm{L}$ & $4.44 \pm 0.9$ & $0.90 \pm 0.36$ & $1.74 \pm 0.1$ & $1.21 \pm 0.13$ & $1.36 \pm 0.14$ \\
\hline $\mathrm{LY}, \%$ & $53.72 \pm 0.7$ & $49.65 \pm 8.6$ & $57.22 \pm 0.9$ & $50.65 \pm 14.65$ & $62.04 \pm 3.93$ \\
\hline $\mathrm{MI}, \%$ & $6.28 \pm 0.4$ & $16.6 \pm 0.0$ & $11.63 \pm 0.1$ & $6.0 \pm 5.3$ & $5.28 \pm 2.4$ \\
\hline $\mathrm{GR}, \%$ & $40.0 \pm 1.4$ & $33.75 \pm 8.6$ & $31.15 \pm 0.2$ & $43.35 \pm 9.3$ & $32.68 \pm 4.6$ \\
\hline $\mathrm{RBC}, \cdot 10^{12} / \mathrm{L}$ & $6.5 \pm 1.2$ & $3.80 \pm 0.27$ & $5.4 \pm 0.1$ & $4.67 \pm 2.58$ & $4.69 \pm 1.36$ \\
\hline $\mathrm{HGB}, \mathrm{g} / \mathrm{L}$ & $140.7 \pm 1.9$ & $77.0 \pm 4.0$ & $105.0 \pm 5.6$ & $86.0 \pm 1.0$ & $86.0 \pm 12.0$ \\
\hline $\mathrm{HCT}, \%$ & $39.8 \pm 1.5$ & $30.85 \pm 0.9$ & $45.2 \pm 0.5$ & $28.10 \pm 0.84$ & $24.69 \pm 2.7$ \\
\hline $\mathrm{MCV}, \mathrm{fl}$ & $55.0 \pm 1.3$ & $43.0 \pm 1.0$ & $48.2 \pm 0.6$ & $40.0 \pm 0.0$ & $42.5 \pm 1.5$ \\
\hline $\mathrm{MCH}, \mathrm{pg}$ & $19.0 \pm 3.6$ & $18.45 \pm 0.2$ & $17.2 \pm 0.1$ & $17.0 \pm 0.3$ & $8.45 \pm 0.55$ \\
\hline $\mathrm{MCHC}, \mathrm{g} / \mathrm{L}$ & $350.6 \pm 2.8$ & $306.5 \pm 2.5$ & $321.0 \pm 8.5$ & $312.5 \pm 6.5$ & $319.25 \pm 4.0$ \\
\hline $\mathrm{RDWC}$ & $14.0 \pm 0.8$ & $13.85 \pm 0.1$ & $14.5 \pm 0.5$ & $13.55 \pm 0.25$ & $12.7 \pm 0.4$ \\
\hline $\mathrm{PLT}, \cdot 10^{9} / \mathrm{L}$ & $660.0 \pm 122.2$ & $74.5 \pm 39.5$ & $315.0 \pm 9.6$ & $107.0 \pm 51.0$ & $318.25 \pm 99.0$ \\
\hline $\mathrm{PCT}, \%$ & $0.44 \pm 0.021$ & $0.05 \pm 0.07$ & $0.34 \pm 0.01$ & $0.032 \pm 0.04$ & $0.31 \pm 0.06$ \\
\hline $\mathrm{MPV}, \mathrm{fl}$ & $7.9 \pm 0.8$ & $5.9 \pm 0.15$ & $7.4 \pm 0.1$ & $4.1 \pm 0.0$ & $6.63 \pm 0.3$ \\
\hline $\mathrm{PDWC}$ & $46.0 \pm 0.8$ & $29.5 \pm 29.5$ & $36.2 \pm 0.9$ & $22.35 \pm 0.65$ & $30.95 \pm 0.25$ \\
\hline
\end{tabular}

As a result of studies, it was found that BIV-95 compound showed leucopoiesis stimulating activity higher than the comparison compound (Levamizole drug).

Toxicity results. For the study of acute toxicity, groups of animals (by 6 animals each) were injected intraperitoneally with the test compound in various doses and observed for 5 days. In mice, external signs of intoxication, the duration of toxic action and the time of animals' death were recorded. For the quantitative assessment of acute toxicity, the $\mathrm{LD}_{50}$ index was calculated (the dose that caused the death of $50 \%$ of the test animals). The reference drug was the pharmaceutical drug $(2,3,5,6$-tetrahydro6-phenylimidazo [2, 1-b] thiazole hydrochloride (Levamizole drug). The degree of toxicity of the drug was judged by $\mathrm{LD}_{50}$ in the experimental and control groups of animals. The $\mathrm{LD}_{50}$ of dimethyl ester of $\mathrm{P}$ [(4-methoxyphenyl)-1-(4-phenylpiperazine) methyl] phosphonic acid compound under the laboratory coding BIV-95 was $721.7 \mathrm{mg} / \mathrm{kg}$, which is 3.6 times lower than the toxicity of the reference compound (Levamizole drug).

\section{Conclusion}

The newly obtained compound dimethyl ether of P-(4-methoxyphenyl)-1-(4-phenylpiperazine) methyl]-phosphonic acid in laboratory coding BIV95 is promising for developing it as a new myeloid stimulating preparation. It shows high myeloid stimulating activity on the model cyclophosphamide myeloid depression. Restoration of leukocyte, erythrocyte, platelet values is more effective than with the comparison compound (2, 3, 5, 6-tetrahydro-6-phenylimidazo [2, 1-b] thiazole hydrochloride (Levamizole drug). It effectively stimulates the regeneration of the leukocyte populations without disturbing the immunoregulatory blood indexes. The test compound had low level of toxicity $721.7 \mathrm{mg} / \mathrm{kg}$, which is 3.6 times lower than the toxicity of reference compound. Test compound dimethyl ether of P-(4-methoxyphenyl)1-(4-phenylpiperazine) methyl]-phosphonic acid in laboratory coding of BIV-95 needs further studies of its pharmacodynamic and pharmacokinetic properties. 


\section{References}

1 Khaitov R.M., Pinegin B.V. (2003) Immunomodulators: the mechanism of action and clinical application. Immunology, vol. 24, no. 4, pp.196-203.

2 Khaitov R.M., Pinegin B.V. (2000) Modern immunomodulators: the basic principles of their use. Immunology, no. 5, pp. 4-7.

3 Hutzschenreuter F., Monsef I., Kreuzer K.A., Engert A., Skoetz N. (2016) Granulocyte and granulocyte-macrophage colony-stimulating factors for newly diagnosed patients with myelodysplastic syndromes. Cochrane Database Syst Rev., vol.16, no.2, pp. 22-28. CD009310. doi: 10.1002/14651858. Review. PMID: 26880256.

4 Novoseletskaya A.V., Kiseleva N.M., Zimina I.V., Bystrova O.V., Belova O.V., Inozemtsev A.N., Arion V.Y., Sergienko V.I. (2015) Thymus polypeptide preparation Tactivin restores learning and memory in thymectomied rats. Bull Exp Biol Med., vol. 159, no. 5, pp. 623-625. doi: 10.1007/s10517-015-3030-6.

5 Ran Y., Xu B., Wang R., Gao Q., Jia Q., Hasan M., Shan S., Ma H., Dai R., Deng Y., Qing H. (2016) Dragon's blood extracts reduce radiationinduced peripheral blood injury and protects human megakaryocyte cells from GM-CSF withdraw-induced apoptosis. Phys Med., vol. 32, no. 1, pp. 84-93. doi: 10.1016/j.ejmp.2015.09.010.

6 Craig M., Humphries A.R., Nekka F., Bélair J., Li J., Mackey M.C. (2015) Neutrophil dynamics during concurrent chemotherapy and G-CSF administration: Mathematical modelling guides dose optimization to minimise neutropenia. $J$ Theor Biol., vol.21, no. 385, pp.77-89. doi: 10.1016/j.jtbi. 2015.08.015. Epub 2015 Sep 3.

7 Praliev K.D., Yu V.K., Fomicheva E.E., Baktybayeva L.K., Svambaev E.A., Tuleukhanov S.T. (2007) Immunostimulants of the N-alkoxyalkyl piperidine series. Chemical Journal of Kazakhstan, no. 2, pp. 180-187.

8 Yu V.K., Praliev K.D., Fomicheva E.E., Baktybayeva L.K., Svambayev E.A., Tuleukhanov S.T. (2007) Immunostimulants based on N-alkoxypiperidines. Chemical Journal of Kazakhstan, no. 2, pp. 180-187.

9 Order of the Minister of Health of the Republic of Kazakhstan dated from November 19, 2009, No. 745 "On approval of the Rules for preclinical (non-clinical) studies of biologically active substances". https://aipm.kz/en/2016-07-11-17-5227/kazakhstan-legislation/424-order-of-the-ministerof-health-and-social-protection-of-the-republic-ofkazakhstan-no-10-dated-january-14-2015.html

10 Doxorubicin hydrochloride. In: European Pharmacopoeia (2005) 6th ed., monograph, pp. 1389-1413.
11 Khaitov R.M., Pinegin B.V., Latysheva T.V. (2002) Methodical instructions for testing new immunomodulating medications. Vedomosti, scientific center of expertise and state control of medicines, no.1, pp. 11-21.

12 Giemsa G. (1904) Eine Vereinfachung und Vervollkommnung meiner Methylenazur-Methylenblau-Eosin-Färbemethode zur Erzielung der Romanowsky-Nochtschen Chromatinfärbung. Centralbl f Bakt etc., no. 37, pp. 308-311. 90.

$13 \mathrm{Yu}$ V.K., Praliyev K.D. (1997) 1-(2-Ethoxyethyl)-4-(dimethylphosphoryl)-4-hydroxypiperidine possess plant growth-stimulating activity. Provisional Patent, no. 5011. Bulletin RK, no. 3, pp. 8-15.

14 Praliyev K.D., Yu V.K., Zhaxibaeva Zh.M., Togyzbaeva N.A., Kemelbekov U.S., Baktybayeva L.K., Svambayev E.A. (2008) Complex of 3-(3-i-propoxypropyl)-7-(2morpholinoethyl)-3,7-diazabicyclo [3.3.1] nonan with $\beta$-cyclodextrin and its precursors synthesis. Provisional Patent, no. 19832. Bulletin RK, no. 8, pp. 6-12.

15 Zimin Yu.S., Borisova N.S., Timerbaeva G.R., Gimadieva A.R., Mustafin A.G. (2016) Obtaining, toxicity and anti-inflammatory activity of complex compounds of uracil derivatives with polyfunctional acids. Chemical-pharm J., vol. 50, no. 10, pp.16-24.

16 Khaitov R.M., Pinegin B.V. (1996) Immunomodulators and some aspects of their clinical use. Clinical medicine, vol. 74, no. 8, pp. 7-12.

17 Kharkevich D.A. Pharmacology. Textbook for high schools. M.: GEOTAR - MED, 2002, 672 p.

18 Hadden, J.W. (1993) Immunostimulants. Immunology Today, vol. 14, pp. 275-280.

19 Werner G.H., Jolles P. (1996) Immunostimulating agents: what next? A review of their present and potential medical applications. European Journal of Immunology, vol. 242, pp. 1-19.

20 Mikhailova A.A. (1996) Individual myelopeptides are "new generation" drugs used for immunorehabilitation. International Journal of Immunoreability, no. 2, pp. 27-31.

21 Petrov R.V., Khaitov R.M., Nekrasov A.V. (1999) Polyoxidonium - immunomodulator of the last generation: results of a three-year clinical application. Allergy, asthma and clinical immunology, no. 3, pp. 3-6.

22 Petrov R.V. (1994) Immunorehabilitation and strategy of medicine. International Journal of Immunoreability, suppl.1, pp. 5-6.

23 Gaetke L.M., Chow C.K. (2003) Copper toxicity, oxidative stress and antioxidant nutrients. Toxicology, vol. 189, pp. 147-163. 